\title{
Research on Carbonation Characteristics and Frost Resistance of Iron Tailings Powder Concrete under Low-Cement Clinker System
}

\author{
Ruidong Wu $\mathbb{D}^{1,2}$ Juanhong Liu $\mathbb{D}^{1,2}$ Guangtian Zhang, ${ }^{1,2,3}$ Yueyue Zhang, \\ and Shuhao An ${ }^{1,2}$ \\ ${ }^{1}$ College of Civil and Resource Engineering, University of Science and Technology Beijing, Beijing 100083, China \\ ${ }^{2}$ Beijing Key Laboratory of Urban Underground Space Engineering, University of Science and Technology Beijing, \\ Beijing 100083, China \\ ${ }^{3}$ Hebei Academy of Building Research, Shijiazhuang 050021, China
}

Correspondence should be addressed to Ruidong Wu; wrd0105@163.com and Juanhong Liu; liujuanhong66@126.com

Received 7 August 2020; Revised 30 September 2020; Accepted 14 October 2020; Published 29 October 2020

Academic Editor: Ibrahim Cavusoglu

Copyright (C) 2020 Ruidong Wu et al. This is an open access article distributed under the Creative Commons Attribution License, which permits unrestricted use, distribution, and reproduction in any medium, provided the original work is properly cited.

The accelerated carbonation, natural carbonation, fast freeze-thaw test, and pore structure analysis of C30 and C50 concrete with different proportions of iron tailings powder and slag powder were tested, respectively. The results show that the accelerated carbonation depth and natural carbonation depth of concrete increase with the increase of iron tailings powder content. The prediction model of carbonation depth of iron tailings powder concrete is established by introducing the iron tailings content coefficient and strength influence coefficient. The error between the calculated value of the model and the test value of $28 \mathrm{~d}$ curing concrete natural carbonation depth is small, which proves that the model is completely feasible. When iron tailings powder accounts for $50 \%$ of mineral admixture, it is helpful to improve the frost resistance of concrete. According to the pore structure analysis, the introduction of iron tailings powder can optimize the pore structure, improve the porosity of harmless and less harmful pores, and thus improve the frost resistance.

\section{Introduction}

Tailings are one of the largest solid wastes in the world, which are widely distributed all over the world. Iron tailings are waste residue discharged from iron ore after beneficiation process, but there is still a lot of space for these solid wastes to be utilized $[1,2]$. The comprehensive utilization rate of tailings is not high, which is limited by the development of beneficiation technology, the restriction of production equipment, and other scientific and technological factors, so the comprehensive utilization of tailings has become a worldwide problem [3-7]. A large number of tailings are piled up in the tailings pond and cannot be used, resulting in a large number of waste resources. The accumulation of these wastes also seriously affects the ecological environment and is a major source of pollution and danger. The consumption of concrete is increasing year by year with the continuous expansion of infrastructure construction. The large use of highperformance concrete results in the huge consumption of mineral admixture. In particular, the frequently used admixtures such as fly ash and slag powder have been in short supply in some areas, which leads to the increase of raw material price and the destruction of market balance. For the sake of economy and environmental protection, it is a good strategy to use iron tailings powder as admixture of concrete, which can not only realize the reuse of iron tailings resources, but also alleviate the actual problem of concrete admixture shortage.

Carbonation and freeze-thaw damage of concrete are important reasons for durability deterioration of concrete [8-12]; the research on carbonation and freeze-thaw of iron tailings powder concrete is the necessary premise to ensure its extensive application. At present, domestic and foreign scholars have some research on the use of iron tailing powder as concrete admixture, mainly focusing on the mechanical properties of concrete [13-17]. There are few reports on the long-term carbonation and frost resistance of concrete mixed with iron tailings powder. It is an important premise for the application of iron tailings powder concrete in engineering practice to clarify the influence of iron 
tailings powder on the long-term carbonation and freezethaw resistance of concrete. In this paper, the influence of the composite admixture of iron tailings powder and slag powder on the long-term carbonation and rapid freeze-thaw is studied. The long-term carbonation law and model of iron tailings powder concrete are established, and the mechanism of iron tailings powder on the concrete freeze-thaw is revealed, which provides a scientific theoretical basis for the extensive application of iron tailings concrete.

\section{Experimental Materials and Methods}

2.1. Raw Materials. The reference cement is used in this experiment, for eliminating experimental errors caused by uncertain components in ordinary cement. The main properties of reference cement are shown in Table 1.

The specific surface area of iron tailings powder is $450 \mathrm{~m}^{2} \cdot \mathrm{kg}^{-1}$, and water demand ratio is $90 \%$, which contains some metal elements such as $\mathrm{Cu}, \mathrm{Fe}, \mathrm{Zn}$, and so on. According to the method of fly ash, the activity index of iron tailings powder is only 64\%. Table 2 shows the main chemical components of iron tailings powder.

The slag powder used is $\mathbf{S 9 5}$ grade, the specific surface area is $485 \mathrm{~m}^{2} \cdot \mathrm{kg}^{-1}$, the water demand ratio is $96.2 \%$, and the density is $2.8 \mathrm{~g} \cdot \mathrm{cm}^{-3}$. All indexes meet the national standards. The particle size distribution of iron tailings powder and slag powder is shown in Figure 1. The particle size of iron tailings powder is slightly coarser than that of slag powder.

The coarse aggregate is divided into big stones (particle size is $10-20 \mathrm{~mm}$ ) and small stones (particle size is $5-10 \mathrm{~mm}$ ), and the mass ratio of big stones and small stones is $8: 2$ in order to accumulate tightly. The fine aggregate is river sand meeting the requirements, and the mud content of river sand is $5.2 \%$. The fineness modulus of river sand is 2.7 , which belongs to medium sand with good gradation. The additive is polycarboxylic acid water reducer with $20 \%$ solid content produced by Sika company.

2.2. Mix Proportion. Two kinds of commonly used concrete (C30 and C50) are prepared in this paper. The proportion of cement in the mix proportion of C30 and C50 concrete is only $30 \%$ and $40 \%$, respectively. This experiment is under low-cement clinker system for the consideration of environmental protection and economy. In order to study the influence of iron tailings powder the content on the performance of concrete, the proportion of iron tailings powder and slag powder is designed as 0:10, 3:7, 5:5, 7:3, and 10:0, respectively. After the preliminary concrete mixing, with the increase of the iron tailings powder content, the water binder ratio of concrete decreases accordingly to ensure that the strength can meet the requirements. Table 3 shows the concrete mix proportion.

2.3. Experimental Methods. Carbonation test is divided into accelerated carbonation and natural carbonation. Accelerated carbonation refers to the fact that the concrete blocks are in standard curing (temperature $20 \pm 2^{\circ} \mathrm{C}$, relative humidity $\geq 95 \%$ ) for 28 days after the concrete formwork is removed. After drying in an oven at $60^{\circ} \mathrm{C}$ for 48 hours, the concrete blocks are put into the carbonation box. The $\mathrm{CO}_{2}$ concentration of the carbonation box is controlled at $(20 \pm 3) \%$, temperature $(20 \pm 2)^{\circ} \mathrm{C}$, and relative humidity $(70 \pm 5) \%$. There are two kinds of curing conditions for natural carbonization: standard curing for 1 day and standard curing for 28 days. The size of the test block is $100 \mathrm{~mm} \times 100 \mathrm{~mm} \times 100 \mathrm{~mm}$ cube. Split the test piece with a press, drop $1 \%$ phenolphthalein alcohol solution, and measure the depth of nondiscoloration from the edge, which is the carbonation depth.

After the concrete is cured under the standard curing condition (temperature $20 \pm 2^{\circ} \mathrm{C}$, relative humidity $\geq 95 \%$ ) for 24 days, soak the concrete in water (temperature $20 \pm 2^{\circ} \mathrm{C}$ ) for 4 days, and put it into the fast freezing and thawing machine at 28 days. The size of concrete quick freezing and thawing test block is $100 \mathrm{~mm} \times 100 \mathrm{~mm} \times 400 \mathrm{~mm}$, and the size of compression strength test block after freezing and thawing is $100 \mathrm{~mm} \times 100 \mathrm{~mm} \times 100 \mathrm{~mm}$. After a certain number of freezing and thawing cycles, the quality, dynamic elastic modulus, and compression strength of the test piece are tested.

\section{Results and Discussion}

3.1. Compressive Strength of Concrete. According to the design mix proportion, the concrete test blocks are formed, and the slump of each group is between 200 and $230 \mathrm{~mm}$, which has good workability. The compressive strength of C30 and C50 concrete for $3 \mathrm{~d}, 7 \mathrm{~d}$, and $28 \mathrm{~d}$ is tested, respectively, as shown in Table 4 .

Table 4 shows that the concrete strength decreases with the increase of iron tailings powder proportion. In C30 concrete, the $28 \mathrm{~d}$ compressive strength of A2 group with $70 \%$ slag powder in mineral admixtures is the highest and that of A5 group with iron tailings powder is the lowest, only 28.6 MPa, which cannot meet the C30 strength requirement. The strength of A 2 and A3 groups is not much different from that of A1 group. Among C50 concrete, the strength of B1 group is the highest at $28 \mathrm{~d}$ and that of B5 group with iron tailings powder is the lowest, only $47.3 \mathrm{MPa}$, which cannot meet the strength requirements of $\mathrm{C} 50$. There is little difference between B2, B3, and B1 groups. Iron tailings powder belongs to inert mineral admixture and does not participate in hydration reaction, so a large amount of iron tailings powder is harmful to the concrete strength, but adding iron tailings powder properly can improve the particle grading and produce microaggregate effect to meet the strength requirements. From the strength point of view, the iron tailings powder should not be mixed alone under the lowcement clinker system. In terms of comprehensive economy and environmental protection, the most reasonable mix proportion is that the ratio of iron tailings powder and slag powder is $5: 5$.

\subsection{Carbonation Depth of Concrete}

3.2.1. Carbonation Depth of Iron Tailings Powder Concrete. The carbonation depth of C30 and C50 concrete placed in the carbonation box for 28 days is tested, respectively. The results are shown in Figure 2. The content of iron tailings 
TABLE 1: Main properties of reference cement.

\begin{tabular}{|c|c|c|c|c|c|c|c|c|c|}
\hline \multicolumn{2}{|c|}{$\begin{array}{l}\text { Setting time } \\
\quad(\min )\end{array}$} & \multicolumn{2}{|c|}{$\begin{array}{l}\text { Compressive } \\
\text { strength }(\mathrm{MPa})\end{array}$} & \multicolumn{2}{|c|}{$\begin{array}{c}\text { Flexural } \\
\text { strength } \\
(\mathrm{MPa})\end{array}$} & \multirow{2}{*}{$\begin{array}{c}\text { Standard } \\
\text { consistency water } \\
\text { consumption (\%) }\end{array}$} & \multirow{2}{*}{$\begin{array}{l}\text { Fineness } \\
(\mathrm{mm})\end{array}$} & \multirow{2}{*}{$\begin{array}{c}\text { Specific } \\
\text { surface } \\
\text { area }\left(\mathrm{m}^{2} \cdot \mathrm{kg}^{-1}\right)\end{array}$} & \multirow[t]{2}{*}{ Soundness } \\
\hline Initial & Final & $3 \mathrm{~d}$ & $28 \mathrm{~d}$ & $3 \mathrm{~d}$ & $28 \mathrm{~d}$ & & & & \\
\hline 155 & 215 & 28.3 & 53.2 & 5.5 & 10.3 & 27.2 & 0.5 & 347 & Qualified \\
\hline
\end{tabular}

TABLE 2: Main chemical composition of iron tailings powder.

\begin{tabular}{lccccccc}
\hline $\begin{array}{l}\text { Chemical } \\
\text { composition }\end{array}$ & $\mathrm{SiO}_{2}$ & $\mathrm{Fe}_{2} \mathrm{O}_{3}$ & $\mathrm{Al}_{2} \mathrm{O}_{3}$ & $\mathrm{CaO}$ & $\mathrm{MgO}$ & $\mathrm{CuO}$ & $\mathrm{ZnO}$ \\
\hline $\begin{array}{l}\text { Mass fraction } \\
(\%)\end{array}$ & 67.59 & 10.88 & 4.57 & 4.02 & 1.18 & 0.23 & 0.11 \\
\hline
\end{tabular}

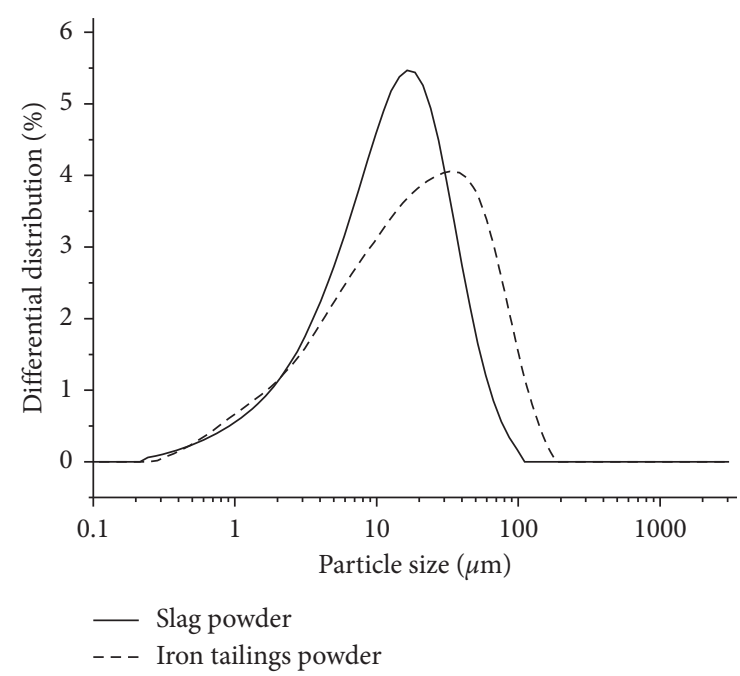

Figure 1: Particle size distribution of iron tailings powder and slag powder.

powder is the mass percentage of iron tailings in the total mineral admixture.

It can be seen from Figure 1 that the accelerated carbonation depth of concrete decreases with the increase of strength, and the carbonation depth of C50 concrete is far less than that of $\mathrm{C} 30$ concrete. In the same strength grade, the carbonation depth increases with the increase of the content of iron tailings powder. The carbonation depth of groups A1 and B1 with single slag powder is the smallest, and the difference of carbonation depth between the group with iron tailings powder accounting for less than $50 \%$ of mineral admixture and the group with single slag powder is small. The carbonation depth of A5 and B5 groups with single iron tailings powder is the largest, which is $285 \%$ and $318 \%$ of that of single slag powder group.

There are two curing conditions for the natural carbonation of concrete, the concrete is placed in the natural environment after curing for $1 \mathrm{~d}$ and $28 \mathrm{~d}$, and the carbonation depth at different ages is tested, as shown in Table 5 .
The effect of curing conditions on the carbonation depth of concrete is very significant. The long-term carbonation depth of concrete placed directly in the natural environment after $1 \mathrm{~d}$ curing is far greater than that after $28 \mathrm{~d}$ standard curing. The activity of iron tailings is low, and the early hydration products mainly come from the hydration of cement and slag. With the introduction of nonactive admixture, the hydration products are less, and the structure is loose, resulting in a large amount of $\mathrm{CO}_{2}$ entering into the concrete, causing carbonation. Therefore, the necessary maintenance is very important for the concrete with nonactive mineral admixture under the low-cement clinker system. The natural carbonation of concrete also shows the rule that the carbonation depth increases with the increase of the content of iron tailings powder. The results show that the carbonation depth of $\mathrm{A} 1$ and $\mathrm{B} 1$ group with slag powder is the smallest and that of A5 and B5 group with iron tailings powder is the largest. The natural carbonation depth of 1080 days after $1 \mathrm{~d}$ curing reaches $190 \%$ and $279 \%$ of A1 and B1 groups.

Based on the natural carbonation and accelerated carbonation of concrete, the iron tailings powder has a great influence on the carbonation depth. Compared with highactivity slag powder, the hydration products of iron tailings powder concrete are less, and the microcompactness of concrete will decrease with the increase of iron tailings powder content. The hydration products in the concrete are less, which leads to structural looseness, and more carbon dioxide is easy to enter into the concrete, resulting in the increase of carbonation depth. The amount of iron tailings powder should not exceed $70 \%$ of the total mineral admixture amount; otherwise, it is very unfavorable to the carbonation resistance of concrete. The adverse effect of iron tailings powder on the carbonation resistance of high strength concrete (C50) is greater than that of low-strength concrete (C30). Therefore, the amount of iron tailings powder in high-strength concrete should be appropriately reduced.

\subsubsection{Carbonation Model of Iron Tailings Powder Concrete.} From the experimental results, the proportion of iron tailings powder in mineral admixture and concrete strength are two important factors affecting the carbonation depth of iron tailings powder concrete. Referring to the durability evaluation standard of concrete structure [18] and the research of some scholars $[19,20]$, the coefficient of iron tailings content and strength influence coefficient are introduced, and the carbonation depth model is proposed: 
TABLE 3: Concrete mix proportion $\left(\mathrm{kg} \cdot \mathrm{m}^{-3}\right)$.

\begin{tabular}{cccccccccc}
\hline & Group & Cement & Slag powder & Iron tailings powder & Stone & Sand & Water & W/B & PC \\
\hline \multirow{6}{*}{ C30 } & A1 & 113 & 264 & 0 & 79 & 1018 & 840 & 151 & 0.40 \\
& A2 & 113 & 185 & 132 & 1018 & 840 & 147 & 0.39 & 3.39 \\
& A3 & 113 & 132 & 185 & 1018 & 840 & 143 & 0.38 & 3.39 \\
& A4 & 113 & 79 & 264 & 1018 & 840 & 140 & 0.37 & 3.39 \\
& A5 & 113 & 0 & 0 & 1018 & 840 & 136 & 0.36 & 3.39 \\
\hline \multirow{5}{*}{ C50 } & B1 & 191 & 287 & 86 & 1071 & 725 & 139 & 0.29 & 6.69 \\
& B2 & 191 & 201 & 143.5 & 1071 & 725 & 134 & 0.28 \\
& B3 & 191 & 143.5 & 201 & 1071 & 725 & 129 & 0.27 \\
& B4 & 191 & 86 & 287 & 1071 & 725 & 124 & 0.26 \\
& B5 & 191 & 0 & & 1071 & 725 & 119 & 0.69 \\
\hline
\end{tabular}

TABle 4: Compressive strength of C30 and C50 concrete (MPa).

\begin{tabular}{cccccccc}
\hline & $3 \mathrm{~d}$ & $7 \mathrm{~d}$ & $28 \mathrm{~d}$ & & $3 \mathrm{~d}$ & $7 \mathrm{~d}$ & $28 \mathrm{~d}$ \\
\hline $\mathrm{A} 1$ & 14.4 & 28.7 & 35.5 & B1 & 24.9 & 50.2 & 71.4 \\
$\mathrm{~A} 2$ & 11.3 & 26.8 & 36.3 & B2 & 22.1 & 48.7 & 64.4 \\
$\mathrm{~A} 3$ & 9.6 & 23.9 & 34.8 & B3 & 19.8 & 44.9 & 64.1 \\
$\mathrm{~A} 4$ & 6.9 & 19.1 & 32.9 & B4 & 15.7 & 34.5 & 53.8 \\
$\mathrm{~A} 5$ & 4.2 & 17.4 & 28.6 & B5 & 8.1 & 29.9 & 47.3 \\
\hline
\end{tabular}

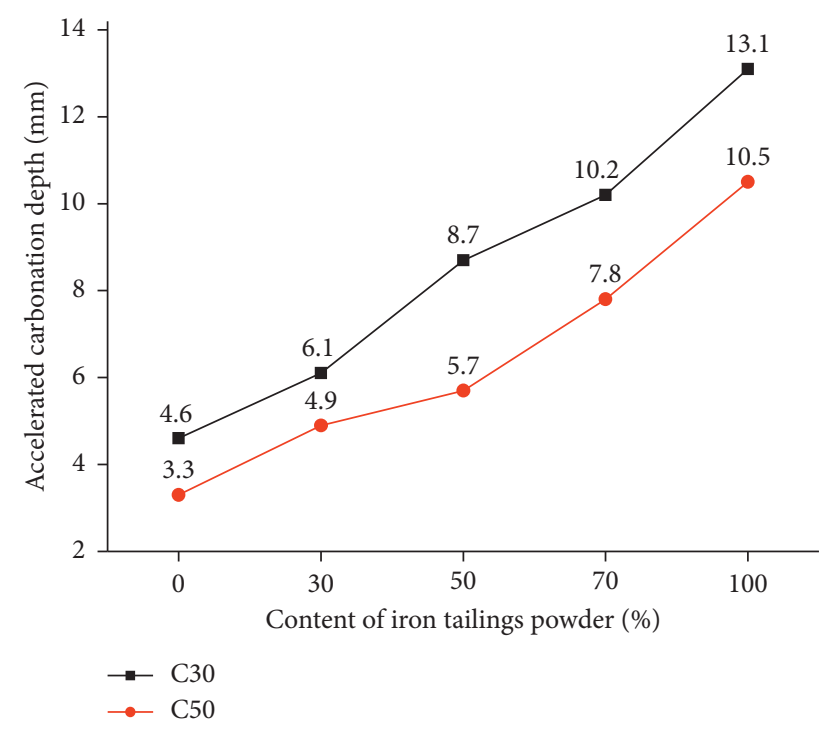

FIgURE 2: $28 \mathrm{~d}$ accelerated carbonization depth of concrete.

$$
\begin{aligned}
X(t) & =3 K_{\mathrm{CO}_{2}} \cdot K_{1} \cdot K_{2} \cdot K_{3} \cdot K_{T} \cdot K_{E} \cdot K_{F} \sqrt{t}, \\
K_{\mathrm{CO}_{2}} & =\sqrt{\frac{C_{0}}{0.03}}, \\
K_{E} & =T^{1 / 4} \mathrm{RH}^{1.5}(1-\mathrm{RH}),
\end{aligned}
$$

where $X(t)$ represents the carbonation depth of $t$ age, $\mathrm{mm}$. $K_{\mathrm{CO}_{2}}$ represents the influence coefficient of $\mathrm{CO}_{2}$ concentration. $C_{0}$ is $\mathrm{CO}_{2}$ concentration, $\% . K_{1}$ is the influence factor of location, taking 1.0. $K_{2}$ is the influence coefficient of curing and pouring, taking 1.2. $K_{3}$ is the influence coefficient of working stress, taking 1.0. $K_{E}$ is the influence coefficient of environment. $t$ is the ambient temperature, ${ }^{\circ} \mathrm{C}$. $\mathrm{RH}$ is the relative humidity, \%. $K_{T}$ and $K_{F}$ represent the content coefficient and strength influence coefficient of iron tailings, respectively.

$K_{T}$ and $K_{F}$ in formula (1) can be fitted according to the test results of $28 \mathrm{~d}$ accelerated carbonization. Firstly, based on the carbonation depth of group A1 and B1 with single slag powder, and the ratio of the carbonation depth of concrete with iron tailings powder different amount and that of concrete with single slag powder as the relative carbonation depth, the relationship between the amount of iron tailings powder and the relative carbonation depth is established, so that $K_{T}$ is determined. Then, $K_{F}$ is calculated according to the experiment data, and the relationship between $K_{F}$ and concrete compressive strength is established.

Figure 3 shows the relationship between the content of iron tailings powder and the relative carbonation depth. Through data fitting, the relationship between the iron tailings content influence coefficient $K_{T}$ on carbonation and the iron tailings proportion $\alpha$ in mineral admixture is as follows:

$$
K_{T}=0.775 \alpha^{2}+1.27 \alpha+0.987
$$

After the iron tailings content coefficient $K_{T}$ was determined, $K_{F}$ is calculated according to the experimental value of carbonation depth, and then the relationship between the strength influence coefficient and the average $28 \mathrm{~d}$ compressive strength of concrete is established. According to Figure $4, K_{F}$ can be calculated by the compressive strength $f_{c u}$, and the formula is

$$
K_{F}=\frac{7.931}{f_{c u}}+0.226 .
$$

Due to the retention of significant figures, the fitting correlation shown in Figure 3 seems to be small, but its correlation coefficient is 0.889 , and the true correlation is much larger than that shown in the figure. By substituting formulae (2) and (3) into formula (1), the carbonation model of iron tailings powder concrete is obtained. Combined with the average temperature and average relative humidity of Beijing in three years and the $\mathrm{CO}_{2}$ concentration under the natural carbonization test conditions, the carbonization depth of different ages is calculated according to the 
TABle 5: Natural carbonization depth of concrete (mm).

\begin{tabular}{|c|c|c|c|c|c|c|c|c|c|c|c|c|}
\hline \multirow{2}{*}{ Group } & \multicolumn{6}{|c|}{ Carbonation depth after $1 \mathrm{~d}$ curing } & \multicolumn{6}{|c|}{ Carbonation depth after $28 \mathrm{~d}$ curing } \\
\hline & $28 \mathrm{~d}$ & $90 \mathrm{~d}$ & $180 \mathrm{~d}$ & $360 \mathrm{~d}$ & $720 \mathrm{~d}$ & $1080 \mathrm{~d}$ & $28 \mathrm{~d}$ & $90 \mathrm{~d}$ & $180 \mathrm{~d}$ & $360 \mathrm{~d}$ & $720 \mathrm{~d}$ & $1080 \mathrm{~d}$ \\
\hline A1 & 2.4 & 3.1 & 3.9 & 6.0 & 9.8 & 11.9 & 0 & 0.1 & 0.4 & 0.8 & 1.1 & 1.4 \\
\hline A2 & 2.5 & 3.6 & 5.1 & 7.4 & 12.2 & 13.6 & 0 & 0.2 & 0.8 & 1.1 & 1.6 & 1.9 \\
\hline A3 & 3.0 & 4.7 & 5.4 & 7.5 & 12.6 & 14.8 & 0.1 & 0.3 & 1.0 & 1.2 & 1.8 & 2.4 \\
\hline A4 & 4.5 & 6 & 6.6 & 9.1 & 14.8 & 17.1 & 0.3 & 0.5 & 1.2 & 1.5 & 2.5 & 2.9 \\
\hline A5 & 6.1 & 8.6 & 9.3 & 11.9 & 18.6 & 22.5 & 0.4 & 0.8 & 1.4 & 2.4 & 3.6 & 4.1 \\
\hline B1 & 1.1 & 1.9 & 2.2 & 3.5 & 5.6 & 6.8 & 0 & 0 & 0 & 0.3 & 0.8 & 0.9 \\
\hline B2 & 1.8 & 3.0 & 3.9 & 5.2 & 8.8 & 10.7 & 0 & 0 & 0.3 & 0.8 & 1.4 & 1.6 \\
\hline B3 & 2.6 & 3.5 & 4.2 & 5.5 & 10.1 & 12.6 & 0 & 0.1 & 0.5 & 0.9 & 1.6 & 1.8 \\
\hline B4 & 2.8 & 3.8 & 4.8 & 7.8 & 12.7 & 15.5 & 0 & 0.2 & 1.0 & 1.5 & 2.1 & 2.4 \\
\hline B5 & 3.3 & 5.4 & 6.5 & 9.4 & 15.6 & 18.8 & 0.2 & 0.6 & 1.1 & 2.1 & 2.9 & 3.3 \\
\hline
\end{tabular}



Figure 3: $K_{T^{-}} \alpha$ relationship.

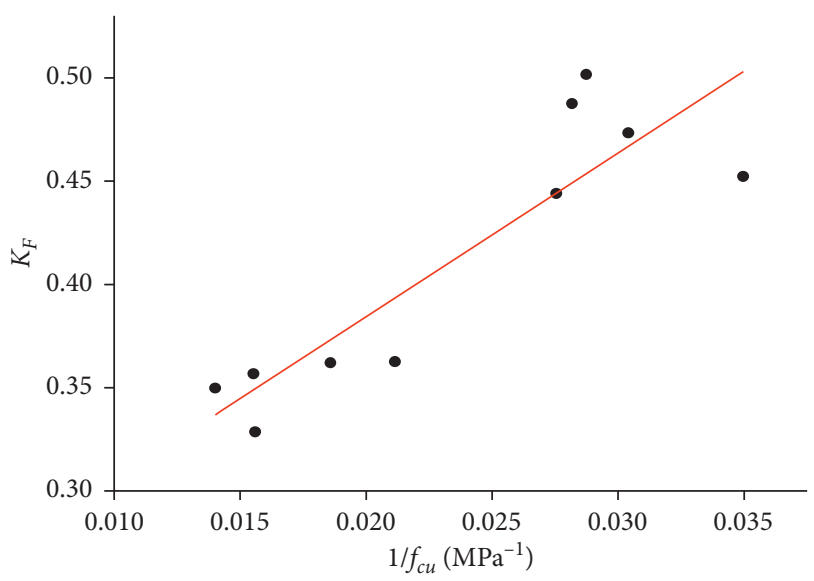

FIGURE 4: $K_{F}-f_{c u}$ relationship.

carbonization model, and compared with the long-term depth of the natural carbonization experiment after 28 days of standard maintenance. The results are shown in Table 6.

Through the comparison between the calculated value of the model and the measured value of the experiment, the error between them is small. Through the verification of long-term natural carbonation experiment, the established carbonation depth model has high reliability, which can effectively predict the carbonation depth of iron tailings fine powder concrete for a long time. The prediction model is suitable for the prediction of long-term carbonation depth of concrete with iron tailings powder and slag powder as compound admixture in low-cement clinker system.

3.2.3. Natural Carbonation Depth Law of Concrete after $1 d$ Curing. There are great differences in the curing conditions in the actual project, so it is necessary to study the long-term carbonation law of concrete with poor curing conditions. Figure 5 shows the development of natural carbonation depth of C30 and C50 concrete with age after $1 \mathrm{~d}$ standard curing. The content of iron tailing powder has great influence on natural carbonation. The larger the content of iron tailing powder is, the greater the carbonation depth is. The influence of iron tailing powder content on the carbonation depth of C50 concrete is greater than that of C30 concrete. In order to better explore the long-term development law of natural carbonation of iron tailing fine powder concrete, the equation of carbonation depth of each group of concrete with time is fitted with the test data, as shown in Table 7.

From the fitting results, the long-term carbonation depth of concrete meets the equation $X=a t^{b}$. In the equation, the coefficient " $a$ " increases with the increase of the iron tailing powder content, while the coefficient " $a$ " and coefficient " $b$ " of C50 concrete mixed with slag powder and iron tailing powder have little difference. The equation coefficient " $a$ " of single mineral powder or iron tailing powder is quite different, but the coefficient " $b$ " of C50 five groups equations is between 0.54 and 0.59 , which has a good correlation. The coefficient " $b$ " of C30 concrete is between 0.42 and 0.57 , and the difference of coefficient " $a$ " is large, which shows the law of increasing with the increase of the iron tailings powder content. The " $b$ " value of the equation is higher than that of the normal cement system. The reason may be that in the low-cement clinker system, the cement consumption only accounts for $30 \%$ of the cementitious materials, so a large number of inactive admixtures makes the " $b$ " value higher than that of the cement system. The law of long-term concrete natural carbonation after $1 \mathrm{~d}$ curing can be explored by using the fitting equation, which lays a theoretical foundation for engineering applications of iron tailing powder in concrete. 
TABLE 6: Comparison between calculated value of carbonization model and natural carbonation experiment value ( $\mathrm{mm}$ ).

\begin{tabular}{|c|c|c|c|c|c|c|}
\hline \multirow{2}{*}{ Group } & \multicolumn{2}{|c|}{$360 \mathrm{~d}$ carbonization depth } & \multicolumn{2}{|c|}{$720 \mathrm{~d}$ carbonization depth } & \multicolumn{2}{|c|}{$1080 \mathrm{~d}$ carbonization depth } \\
\hline & Calculated & Experiment & Calculated & Experiment & Calculated & Experiment \\
\hline $\mathrm{A} 1$ & 0.8 & 0.69 & 1.1 & 0.97 & 1.4 & 1.19 \\
\hline $\mathrm{A} 2$ & 1.1 & 0.99 & 1.6 & 1.40 & 1.9 & 1.72 \\
\hline $\mathrm{A} 3$ & 1.2 & 1.28 & 1.8 & 1.81 & 2.4 & 2.21 \\
\hline A4 & 1.5 & 1.63 & 2.5 & 2.31 & 2.9 & 2.83 \\
\hline A5 & 2.4 & 2.37 & 3.6 & 3.35 & 4.1 & 4.10 \\
\hline B1 & 0.3 & 0.52 & 0.8 & 0.73 & 0.9 & 0.90 \\
\hline $\mathrm{B} 2$ & 0.8 & 0.78 & 1.4 & 1.10 & 1.6 & 1.35 \\
\hline B3 & 0.9 & 0.98 & 1.6 & 1.39 & 1.8 & 1.71 \\
\hline B4 & 1.5 & 1.31 & 2.1 & 1.85 & 2.4 & 2.26 \\
\hline B5 & 2.1 & 1.85 & 2.9 & 2.62 & 3.3 & 3.21 \\
\hline
\end{tabular}

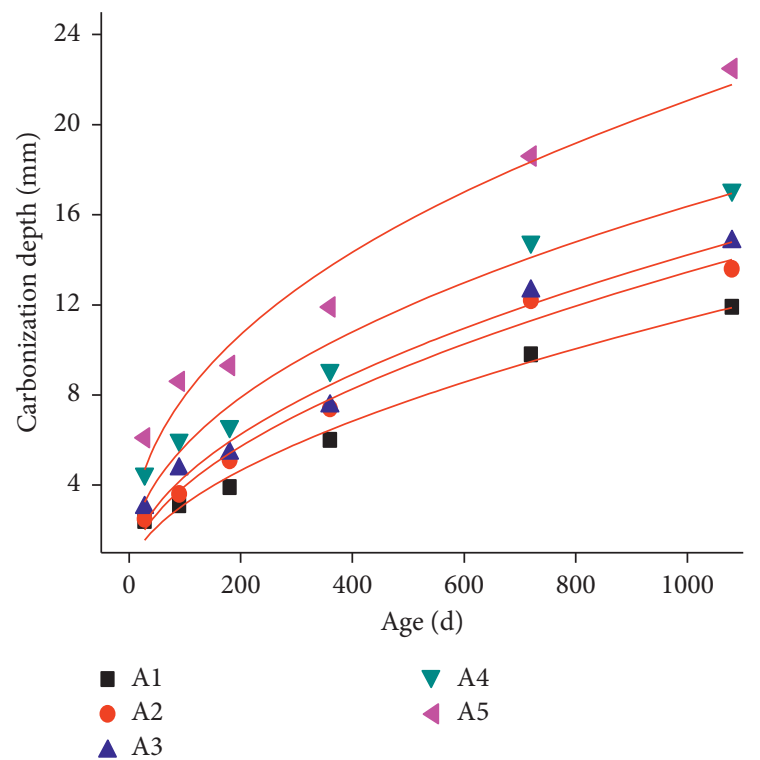

(a)

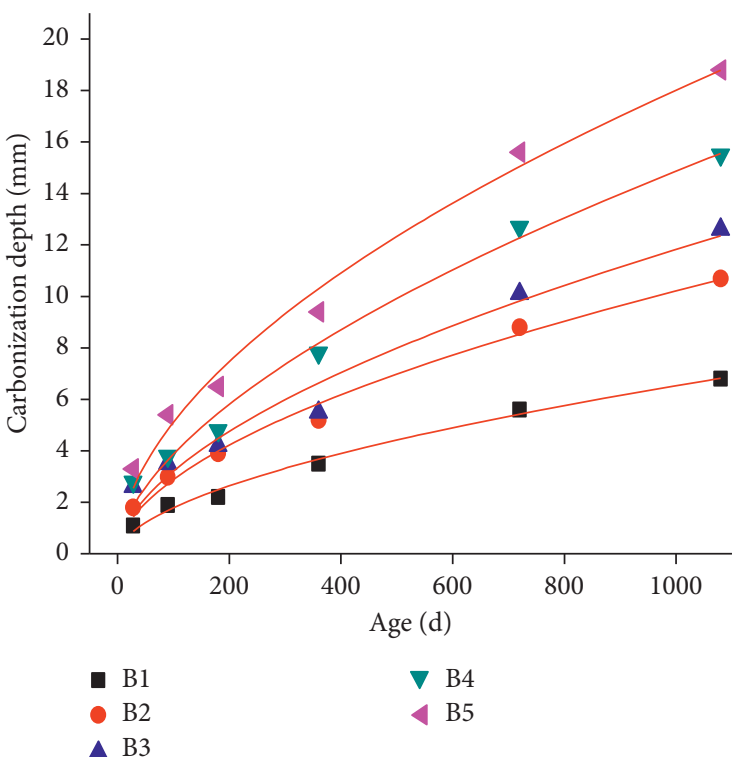

(b)

FIGURE 5: Natural carbonation depth of iron tailings powder concrete after $1 \mathrm{~d}$ curing. (a) C30. (b) C50.

TABLE 7: Time-carbonation depth fitting equation for iron tailings concrete.

\begin{tabular}{llcc}
\hline Group & Equation & Group & Equation \\
\hline A1 & $X=0.243 t^{0.556}$ & B1 & $X=0.134 t^{0.562}$ \\
A2 & $X=0.341 t^{0.532}$ & B2 & $X=0.231 t^{0.548}$ \\
A3 & $X=0.418 t^{0.510}$ & B3 & $X=0.238 t^{0.566}$ \\
A4 & $X=0.712 t^{0.453}$ & B4 & $X=0.263 t^{0.584}$ \\
A5 & $X=1.148 t^{0.421}$ & B5 & $X=0.412 t^{0.547}$ \\
\hline
\end{tabular}

\subsection{Frost Resistance of Iron Tailings Powder Concrete}

3.3.1. Fast Freeze-Thaw Test of Concrete. When the concrete is damaged by freeze-thaw, its most remarkable feature is that the concrete surface will produce erosion phenomenon, so the quality of concrete will be lost. The mass loss rate of concrete shall be calculated according to the following formula:

$$
\Delta W_{n}=\frac{W_{0}-W_{n}}{W_{0}} \times 100 \%,
$$

where $W_{0}$ represents the quality of concrete before rapid freeze-thaw, $W_{n}$ represents the quality of concrete after fast freeze-thaw $n$ cycle, and $\Delta W_{n}$ represents the mass loss rate of concrete after fast freeze-thaw $n$ cycle.

With the increase of freeze-thaw cycles, the cement paste on the concrete surface began to fall off and the aggregate gradually exposed. This phenomenon mainly occurred at the end of the concrete specimen. The surface erosion of concrete groups A5 and B5 mixed with iron tailing powder was the most serious. The quality of each group concrete decreases with the increase of freeze-thaw cycles. The mass loss of C30 and C50 concrete along with the freeze-thaw times is shown in Table 8.

Proper addition of iron tailing powder can reduce the mass loss rate of concrete after rapid freeze-thaw. In C30 and C50 concrete, the mass loss rate of concrete is less than $5 \%$ before the cycle of freeze-thaw damage. Group A5 and group B5 with single iron tailings powder have the largest mass loss rate and the worst frost resistance. The reason is that the iron tailing powder is a kind of inactive mineral admixture, which 
TABLE 8: Mass loss rate of iron tailings powder concrete in different freeze-thaw cycles.

\begin{tabular}{lccccccc}
\hline Cycle index & 50 & 100 & 150 & 200 & 250 & 300 & 350 \\
\hline A1 & $0.5 \%$ & $2.1 \%$ & $\mathbf{4 . 4 \%}$ & & & & \\
A2 & $0.6 \%$ & $2.2 \%$ & $\mathbf{4 . 1 \%}$ & & & & \\
A3 & $0.1 \%$ & $0.7 \%$ & $1.4 \%$ & $\mathbf{1 . 8} \%$ & & & \\
A4 & $0.4 \%$ & $1.1 \%$ & $1.7 \%$ & $\mathbf{2 . 3} \%$ & & & \\
A5 & $1.1 \%$ & $\mathbf{4 . 5 \%}$ & & & & & \\
B1 & $0.3 \%$ & $1.1 \%$ & $1.5 \%$ & $2.8 \%$ & $\mathbf{4 . 5 \%}$ & & \\
B2 & $0.2 \%$ & $0.8 \%$ & $1.3 \%$ & $1.9 \%$ & $2.7 \%$ & $\mathbf{4 . 1 \%}$ & \\
B3 & $0.1 \%$ & $0.4 \%$ & $0.9 \%$ & $1.2 \%$ & $1.9 \%$ & $3.2 \%$ & $\mathbf{3 . 5 \%}$ \\
B4 & $0.1 \%$ & $0.8 \%$ & $1.1 \%$ & $1.6 \%$ & $2.6 \%$ & $\mathbf{3 . 8 \%}$ & \\
B5 & $1.0 \%$ & $1.8 \%$ & $2.5 \%$ & $\mathbf{4 . 2} \%$ & & & \\
\hline
\end{tabular}

does not participate in the hydration reaction at the age of 28 days, and there are less cementitious substances in the hydration products of concrete. After the freeze-thaw cycle, a large amount of iron tailing powder will fall off at the edge of the test piece, resulting in a large loss of quality. In C30 concrete, when the ratio of iron tailings powder and slag powder is $5: 5,7: 3$, the mass loss of concrete is lower than that of single slag powder, and when the ratio of iron tailings powder and slag powder is 3:7, the mass loss of pure slag powder is closer. In C50 concrete, when the ratio of iron tailings powder and slag powder is $3: 7,5: 5$, and 7:3, the mass loss of the same freeze-thaw cycle times is lower than that of B1 group. For example, after 250 freeze-thaw cycles, the mass loss of group B1 concrete mixed with slag powder is $4.5 \%$. The concrete shows obvious erosion phenomenon, and the aggregate is exposed. The mass loss rate of group B3 concrete with the ratio 5:5 of iron tailings powder and slag powder is only $1.9 \%$, which is far lower than that of group $\mathrm{B} 1$. The concrete shows that there is no obvious shedding phenomenon, as shown in Figure 6. The results show that the quality loss of concrete after rapid freeze-thaw can be reduced by adding iron tailing powder properly. When the proportion of iron tailing powder and slag powder is 5:5, the quality loss of concrete is the smallest and the frost resistance is the best.

Another important index of concrete freeze-thaw cycle is the relative dynamic elastic modulus of concrete. The dynamic elastic modulus of concrete with different amounts of iron tailing powder after different freeze-thaw cycles is tested, respectively. Compared with the initial dynamic elastic modulus, the relative dynamic elastic modulus is calculated. When the relative dynamic elastic modulus drops below $60 \%$ of the initial modulus, the test is terminated. Table 9 shows the residual dynamic elastic modulus of concrete with different freeze-thaw cycles.

Appropriate addition of iron tailings powder is helpful to improve the residual relative dynamic elasticity modulus of the concrete after rapid freeze-thaw cycles. The influence of freeze-thaw cycles on the relative dynamic elasticity modulus is greater than the mass loss in the iron tailings powder concrete. The residual relative dynamic elasticity modulus of A5 and B5 groups with single iron tailings powder mixed is the smallest, and the ability to resist freeze-thaw damage is the worst. In C30 and C50 concrete, when the ratio of iron tailings powder and slag powder is $3: 7,5: 5$, and 7:3, the residual relative dynamic elasticity modulus of concrete is much larger than that of single slag powder group. For example, in C50 concrete, after 250 cycles of rapid freezethaw, the residual relative dynamic elasticity modulus of B1 group concrete mixed with slag powder is $53.6 \%$, and the concrete has been damaged by freeze-thaw. The mass loss rate of $\mathrm{B} 3$ group is $67.1 \%$ when the ratio of iron tailings powder to slag powder is $5: 5$, which is much higher than that of $\mathrm{B} 1$ group. The results show that the residual relative dynamic elasticity modulus of concrete can be increased by adding iron tailings powder properly. When the proportion of iron tailings powder and slag powder is 5:5, the relative dynamic elasticity modulus of concrete decreases the least and the frost resistance is the best.

According to GBT 50082-2009 standard for test method of long-term performance and durability of ordinary concrete, if the mass loss of concrete is more than $5 \%$ or the residual dynamic elasticity modulus is less than $60 \%$, it can be regarded as the failure state of concrete during rapid freezing and thawing. The frost resistance of C30 and C50 concrete mixed with single slag powder is F100 and F200, while that of C30 and C50 concrete mixed with single iron tailings powder is the worst, only F50 and F150. When the ratio of tailings powder and slag powder is $5: 5$, the frost resistance of concrete is the best: C30 concrete reaches F150, and C50 concrete reaches F300; adding iron tailings powder properly is beneficial to improve the frost resistance of concrete.

\subsubsection{Compressive Strength of Concrete after Fast Freeze-} Thaw. In order to explore the influence of fast freeze-thaw on the compressive strength of concrete, the concrete specimen with the size of $100 \mathrm{~mm} \times 100 \mathrm{~mm} \times 100 \mathrm{~mm}$ was put into the fast freeze-thaw test machine. After a certain number of freeze-thaw cycles, take the test piece out of the freeze-thaw box and test the compressive strength of the concrete, as shown in Table 10.

The compressive strength of concrete decreases with the increase of freeze-thaw cycles. The compressive strength of concrete mixed with slag powder is the highest before freezethaw cycles, but the compressive strength of concrete mixed with slag powder decreases rapidly after freeze-thaw cycles. In C30 concrete, the compressive strength of A1 group concrete is lower than that of A2, A3, and A4 group after 50 freeze-thaw cycles. In C50 concrete, the compressive strength of B1 concrete is lower than that of B2 and B3 concrete after 150 freeze-thaw cycles. This shows that the proper addition of iron tailings powder can not only improve the frost resistance of concrete, but also improve the bearing capacity of concrete after freeze-thaw.

Based on the compressive strength before freeze-thaw, the loss rate of compressive strength after the specified freeze-thaw times and before freeze-thaw is calculated, and the influence of iron tailing powder on the loss rate of concrete freeze-thaw strength is studied, as shown in Figure 7. 


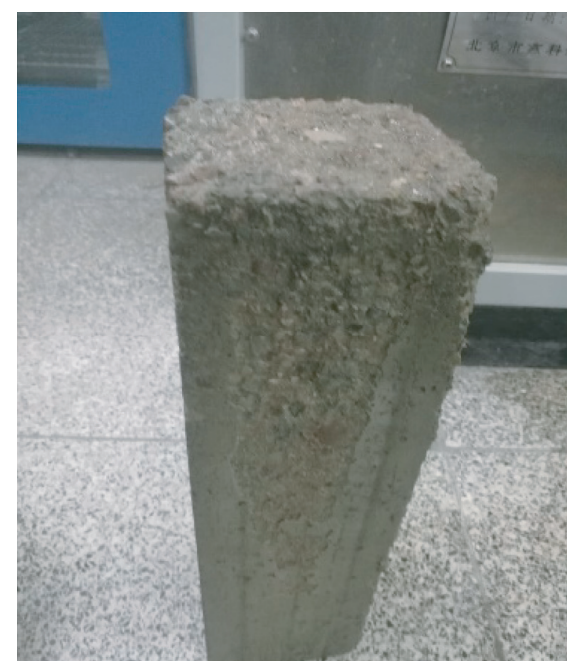

(a)

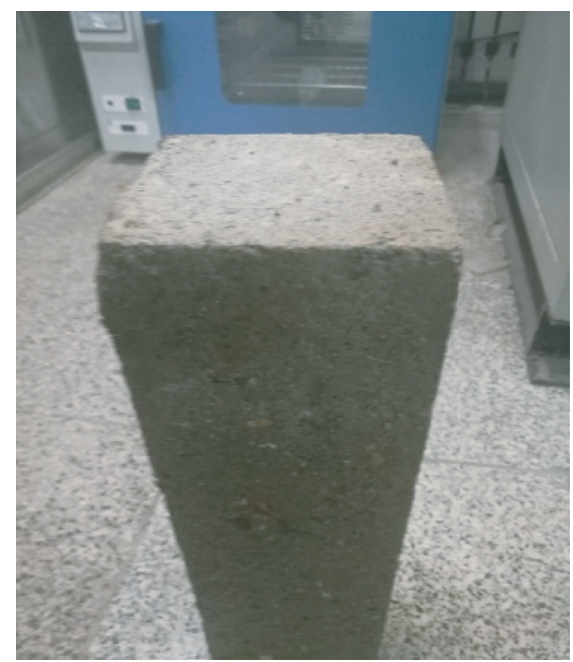

(b)

FIgURE 6: Appearance of C50 concrete after 250 freeze-thaw cycles. (a) B1. (b) B3.

TABle 9: Residual dynamic elastic modulus of concrete with different freeze-thaw cycles.

\begin{tabular}{lccccccc}
\hline $\begin{array}{l}\text { Cycle } \\
\text { index }\end{array}$ & 50 & 100 & 150 & 200 & 250 & 300 & 350 \\
\hline A1 & $85.4 \%$ & $66.1 \%$ & $\mathbf{5 5 . 2} \%$ & & & & \\
A2 & $86.5 \%$ & $70.5 \%$ & $\mathbf{5 8 . 4 \%}$ & & & & \\
A3 & $88.2 \%$ & $75.4 \%$ & $62.2 \%$ & $\mathbf{5 7 . 7 \%}$ & & & \\
A4 & $88 \%$ & $73.7 \%$ & $66.1 \%$ & $\mathbf{5 8 . 9} \%$ & & & \\
A5 & $77.2 \%$ & $\mathbf{5 8 . 0 \%}$ & & & & & \\
B1 & $93.2 \%$ & $86.1 \%$ & $73.2 \%$ & $64.7 \%$ & $\mathbf{5 3 . 6 \%}$ & & \\
B2 & $94.3 \%$ & $87.2 \%$ & $76.8 \%$ & $69.1 \%$ & $63.7 \%$ & $\mathbf{5 5 . 8} \%$ & \\
B3 & $96.8 \%$ & $90.5 \%$ & $82.9 \%$ & $72.2 \%$ & $67.1 \%$ & $64.3 \%$ & $\mathbf{5 7 . 5 \%}$ \\
B4 & $95.4 \%$ & $89.1 \%$ & $79.5 \%$ & $71.3 \%$ & $64.5 \%$ & $\mathbf{5 8 . 1} \%$ & \\
B5 & $90.4 \%$ & $84.5 \%$ & $70.3 \%$ & $\mathbf{5 9 . 3} \%$ & & & \\
\hline
\end{tabular}

TABle 10: Compressive strength of concrete after different freezethaw cycles.

\begin{tabular}{lcccccccc}
\hline Group & 0 & 50 & 100 & 150 & 200 & 250 & 300 & 350 \\
\hline A1 & 35.5 & 32.3 & 26.5 & 24.8 & & & & \\
A2 & 36.3 & 34.8 & 31.1 & 28.1 & & & & \\
A3 & 34.8 & 32.7 & 31.5 & 29.6 & 27.4 & & & \\
A4 & 32.9 & 30.5 & 29.6 & 27.5 & 24.1 & & & \\
A5 & 28.6 & 24.3 & 20.9 & & & & & \\
B1 & 71.4 & 68.8 & 64.1 & 59.3 & 54.1 & 50.8 & & \\
B2 & 64.4 & 61.5 & 59.3 & 57.5 & 55.9 & 54.3 & 51.5 & \\
B3 & 64.1 & 63.9 & 62.5 & 61.1 & 59.3 & 56.5 & 55.0 & 51.9 \\
B4 & 53.8 & 51.5 & 49.1 & 47.6 & 44.4 & 42.9 & 41.2 & \\
B5 & 47.3 & 43.4 & 37.6 & 33.1 & 29.5 & & & \\
\hline
\end{tabular}

From the view of strength loss rate, the loss rate of strength concrete mixed with iron tailings powder is the largest with the increase of freeze-thaw cycles. The compressive strength of concrete mixed with slag powder is higher before freeze-thaw cycle, but the strength loss rate with freeze-thaw failure is also higher. The strength loss rate of the concrete with $30 \%, 50 \%$, and $70 \%$ iron tailings powder is less than that of concrete with slag powder alone. The strength loss rate of C30 and C50 concrete after freeze-thaw cycle is almost the same. When the concrete is only mixed with slag powder, the strength loss rate is about $30 \%$, while the concrete with slag powder and iron tailings powder ratio of $5: 5$ is only about $20 \%$. When the ratio of iron tailings powder and slag powder is 5:5, the concrete has the highest freeze-thaw resistance and the lowest strength loss rate.

3.3.3. Pore Structure Analysis of Iron Tailings Powder Concrete before and after Freezing and Thawing. In order to explore the mechanism of iron tailings powder to improve the frost resistance, the pore structure distribution in concrete was tested by NMR, and the total porosity and different pore size distribution were analyzed. The nuclear magnetic resonance was measured by the MesoMR23-060H-type nuclear magnetic resonance tester with the resonance frequency of $23 \mathrm{MHz}$. Firstly, the concrete samples were saturated with water for more than 24 hours in vacuum; then the samples were taken out, and the porosity and pore size distribution of the concrete samples were measured by ${ }^{1} \mathrm{H}$ NMR analysis. The porosity before freeze-thaw and the porosity after freeze-thaw failure of each group of concrete were tested, respectively; that is, after 150 freeze-thaw cycles for groups A1 and A2, 200 freeze-thaw cycles for groups A3 and A4, 100 freeze-thaw cycles for group A5, 250 freezethaw cycles for group B1, 300 freeze-thaw cycles for groups B2 and B4, 350 freeze-thaw cycles for group B3, and 200 freeze-thaw cycles for group B5. There are four types of holes in concrete. The holes with the aperture less than $0.02 \mu \mathrm{m}$ are harmless holes, the holes with the aperture of $0.02-0.1 \mu \mathrm{m}$ are less harmful holes, the holes with the aperture of $0.1-0.2 \mu \mathrm{m}$ are harmful holes, and the holes with the aperture greater than $0.2 \mu \mathrm{m}$ are multiharmful holes. The porosity of harmless holes, less harmful holes, harmful holes, and more harmful holes in different groups of concrete is calculated by 


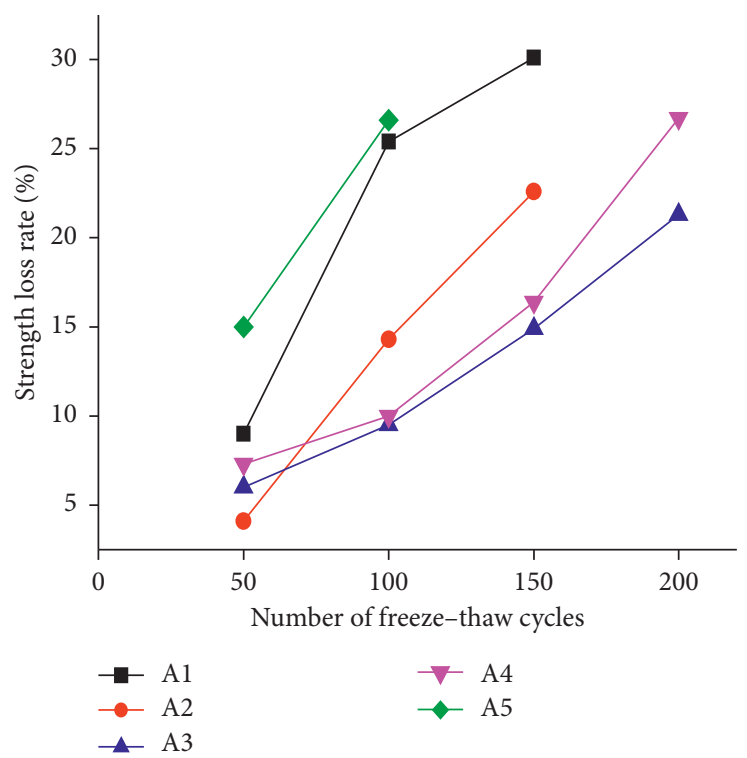

(a)

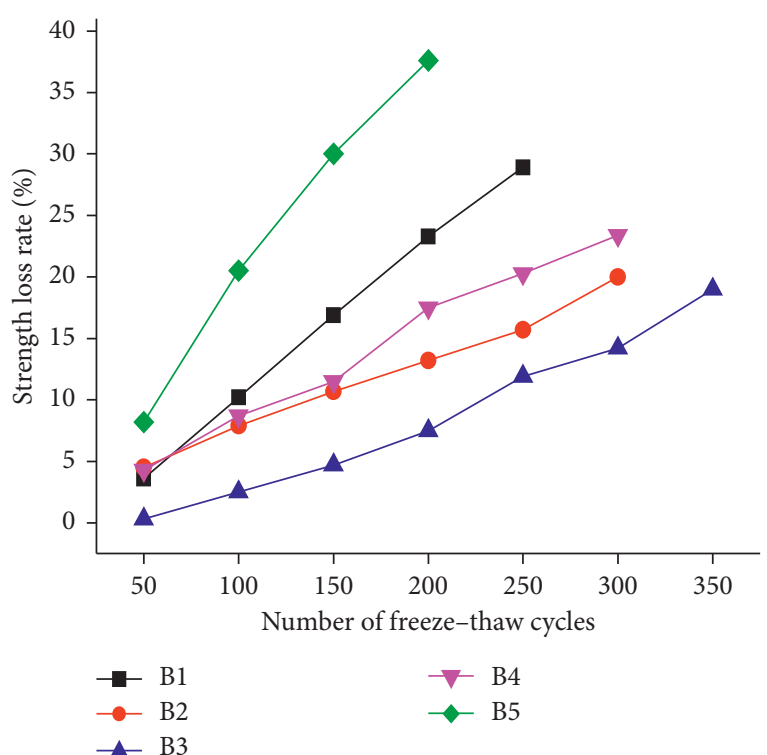

(b)

Figure 7: Strength loss rate of concrete after different freeze-thaw cycles. (a) C30. (b) C50.

using the NMR pore size distribution curve of each group of concrete, as shown in Table 11.

From the analysis of pore size results, after freeze-thaw damage, the proportion of harmless holes and less harmful holes decreased sharply, and the number of harmful holes and more harmful holes increased significantly, resulting in the decline of concrete quality, relative dynamic elastic modulus, and compressive strength. The freeze-thaw damage of concrete is caused by the water in the internal pores forming ice, causing volume expansion and damage. When the water in the pore freezes, the ice pressure and water migration pressure increase continuously. When the pressure exceeds the tensile strength of the concrete, the internal damage of the concrete occurs. With the continuous development of pore volume expansion and the increase of pore diameter, the ratio of harmless pore and less harmful pore space decreases sharply after freeze-thaw damage, and the number of more harmful pores above $0.2 \mu \mathrm{m}$ increases. This kind of damage is from the surface to the inside. The pore water is frozen layer by layer, which causes the surface concrete to peel off and the quality loss. The continuous development of pores causes the internal structure damage of concrete, which affects the dynamic elastic modulus and compressive strength of concrete. The internal expansion stress of concrete is increasing and the internal cracks are expanding continuously, which leads to the decrease of concrete bearing capacity. The macroscopic reaction is that the compressive strength of concrete decreases with the increase of freeze-thaw cycles.

Proper addition of iron tailings powder can increase the harmless pore under $0.02 \mu \mathrm{m}$ in concrete. The frost resistance of concrete is directly related to the porosity of harmless holes and multiple harmful holes before freezing and thawing, that is, the more harmless holes, the less harmful holes, the stronger the frost resistance of concrete.
The freezing point of capillary water is related to the pore size. The smaller the pore size is, the lower the freezing point of water is. The introduction of innocuous holes can play a good buffer role in the freezing expansion of water in the pores, thus reducing the expansion pressure and slowing down the damage of the internal structure of the concrete. With the increase of harmless and less harmful holes in concrete, the expansion stress in freeze-thaw process is significantly reduced, and the crack development speed is slow, which can alleviate the damage rate and degree of concrete quality, dynamic elastic modulus, and compressive strength with freeze-thaw cycle. Although the total porosity of group A3 and B3 is slightly higher than that of groups A1 and $\mathrm{B} 1$, the porosity of less harmful holes is significantly increased, which effectively improves the internal pore structure of concrete, thus increasing the frost resistance of concrete. For example, the total porosity of group A1 concrete before freezing and thawing is $15.47 \%$, the porosity of harmless holes less than $0.02 \mu \mathrm{m}$ is $13.68 \%$, and the porosity of multiple harmful holes greater than $0.2 \mu \mathrm{m}$ is $0.57 \%$. However, the total porosity of group A3 is $16.03 \%$, which is slightly higher than that of group A1. The harmless porosity is $15.24 \%$, which is higher than that of group A1, and the multiple harmful porosity is only $0.10 \%$, which was lower than that of group A1. This is also the reason that the frost resistance and strength of group A3 is better than that of group A1. The number of harmless holes and less harmful holes determines the freeze-thaw resistance of concrete. Groups A3 and B3 with the ratio of iron tailings powder to slag powder of 5:5 have the highest porosity of less harmful holes and harmless holes below $0.1 \mu \mathrm{m}$, so their frost resistance is the best.

The frost resistance of concrete with single iron tailing powder is the worst, because the addition of nonactive iron tailing powder increases the porosity of concrete, and the 
TABle 11: Porosity of concrete (\%).

\begin{tabular}{ccccccccccc}
\hline & \multicolumn{2}{c}{ Total porosity } & \multicolumn{2}{c}{$<0.02 \mu \mathrm{m}$} & \multicolumn{2}{c}{$0.02-0.1 \mu \mathrm{m}$} & \multicolumn{2}{c}{$0.1-0.2 \mu \mathrm{m}$} & \multicolumn{2}{c}{$>0.2 \mu \mathrm{m}$} \\
& Before & After & Before & After & Before & After & Before & After & Before & After \\
\hline A1 & 15.47 & 22.40 & 13.68 & 2.49 & 1.09 & 1.40 & 0.13 & 3.77 & 0.57 \\
A3 & 16.03 & 22.98 & 15.24 & 4.53 & 0.43 & 1.98 & 0.26 & 2.42 & 0.10 \\
A5 & 17.83 & 27.08 & 15.11 & 2.85 & 1.11 & 2.70 & 0.39 & 4.42 & 1.22 & 14.05 \\
B1 & 7.12 & 13.16 & 6.64 & 1.35 & 0.21 & 0.29 & 0.11 & 1.49 & 0.16 & 10.03 \\
B3 & 7.59 & 11.09 & 6.83 & 1.58 & 0.58 & 0.70 & 0.09 & 0.31 & 0.09 \\
B5 & 9.61 & 15.63 & 7.90 & 2.11 & 0.54 & 0.89 & 0.26 & 1.28 & 0.91 & 11.35 \\
\hline
\end{tabular}

number of harmful holes and multiple harmful holes is greatly increased compared with other concrete, especially the increase of multiple harmful holes is several times. In the case of small increase of harmless holes, a large number of multiple harmful holes accelerate the freezing failure rate of concrete. After freeze-thaw, the number of large holes larger than $0.2 \mu \mathrm{m}$ determines the compressive strength of concrete after freeze-thaw damage. It is explained that the compressive strength of $\mathrm{A} 3$ and $\mathrm{B} 3$ has the smallest loss rate with freeze-thaw damage, and A5 and B5 strength loss rate with single iron tailings powder is the largest.

\section{Conclusions}

(1) The concrete strength decreases with the increase of iron tailings powder content, and the carbonation depth increases with the increase of iron tailings powder content. The strength and carbonation resistance of concrete with single iron tailing powder are poor, so the iron tailings powder should not be used alone.

(2) The prediction model of carbonation of iron tailings concrete is established by using the proportion of iron tailings powder in mineral admixture and $28 \mathrm{~d}$ compressive strength. The error between the calculated value and the test value of $360 \mathrm{~d}, 720 \mathrm{~d}$, and $1080 \mathrm{~d}$ concrete carbonation depth is small, and the model is completely feasible, which can predict the long-term carbonation depth.

(3) Adding a certain amount of iron tailings powder can improve the frost resistance. When the ratio of iron tailing powder to slag powder is $5: 5$, the frost resistance of concrete is the best, C30 concrete reaches F150, C50 concrete reaches F300, and the residual compressive strength of concrete after freeze-thaw cycle is effectively improved.

(4) The mechanism of improving the concrete frost resistance by adding appropriate amount of iron tailings powder is to improve the pore structure characteristics, increase the number of harmless holes and less harmful holes, and reduce the number of more harmful holes and harmful holes, so as to improve the frost resistance of concrete.

\section{Data Availability}

The data used to support the findings of this study are included within the article. The data used to support the findings of this study are also available from the corresponding author upon request.

\section{Conflicts of Interest}

The authors declare that there are no conflicts of interest regarding the publication of this paper.

\section{Authors' Contributions}

Juanhong Liu and Ruidong Wu conceived and designed the experiments; Ruidong $\mathrm{Wu}$, Guangtian Zhang, and Yueyue Zhang performed the experiments; Shuhao An contributed materials; and Ruidong $\mathrm{Wu}$ and Juanhong Liu wrote the paper. All authors read and approved the manuscript.

\section{Acknowledgments}

This research was financially supported by the National Natural Science Foundation of China (nos. 51834001 and 51678049).

\section{References}

[1] X. Chen, X. Jin, H. Jiao, Y. Yang, and J. Liu, "Pore connectivity and dewatering mechanism of tailings bed in raking deepcone thickener process," Minerals, vol. 10, no. 4, p. 375, 2020.

[2] R. D. Wu and J. H. Liu, "Experimental study on the concrete with compound admixture of iron tailings and slag powder under low cement clinker system," Advances in Materials Science and Engineering, vol. 2018, Article ID 9816923, 7 pages, 2018.

[3] W. Zhao, C. L. Huo, M. Z. Liu, and H. M. Yang, "Research progress on the comprehensive utilization of non-ferrous metal mine tailings," China Resources Comprehensive Utilization, vol. 29, pp. 24-28, 2011.

[4] Y. Sun, H. Wang, L. Liu, and X. Wang, "Solid wastes utilization in the iron and steel industry in China: towards sustainability," Mineral Processing \& Extractive Metallurgy, vol. 126, no. 1-2, pp. 41-46, 2017.

[5] L. Luo, Y. Zhang, S. Bao, and T. Chen, "Utilization of iron ore tailings as raw material for portland cement clinker production," Advances in Materials Science and Engineering, vol. 2016, Article ID 1596047, 6 pages, 2016.

[6] Z.-x. Tian, Z.-h. Zhao, C.-q. Dai, and S.-j. Liu, "Experimental study on the properties of concrete mixed with iron ore tailings," Advances in Materials Science and Engineering, vol. 2016, Article ID 8606505, 9 pages, 2016.

[7] Z. Zhu, B. Li, and M. Zhou, "The influences of iron ore tailings as fine aggregate on the strength of ultra-high performance concrete," Advances in Materials Science and Engineering, vol. 2015, Article ID 412878, 6 pages, 2015. 
[8] M. Guiglia and M. Taliano, "Comparison of carbonation depths measured on in-field exposed existing r.c. structures with predictions made using fib-model code 2010," Cement and Concrete Composites, vol. 38, no. 2, pp. 92-108, 2013.

[9] J. Geng and J. Sun, "Characteristics of the carbonation resistance of recycled fine aggregate concrete," Construction and Building Materials, vol. 49, no. 1, pp. 814-820, 2013.

[10] J. Tang, J. Wu, Z. Zou, A. Yue, and A. Mueller, "Influence of axial loading and carbonation age on the carbonation resistance of recycled aggregate concrete," Construction and Building Materials, vol. 173, pp. 707-717, 2018.

[11] L. Shen, Q. Li, W. Ge, and S. Xu, "The mechanical property and frost resistance of roller compacted concrete by mixing silica fume and limestone powder: experimental study," Construction and Building Materials, vol. 239, p. 117882, 2020.

[12] Y. Yuan, R. Zhao, R. Li et al., "Frost resistance of fiberreinforced blended slag and class F fly ash-based geopolymer concrete under the coupling effect of freeze-thaw cycling and axial compressive loading," Construction and Building Materials, vol. 250, p. 118831, 2020.

[13] X. Y. Ma, A. L. Wang, and X. Yang, "Study on the influence of iron tailings powder compound admixture on concrete performance," China Concrete, vol. 7, pp. 90-95, 2013.

[14] B. G. Oladeji and S. C. Aduloju, "Investigation of compressive strength of concrete from cement and iron-ore tailings mixture," Scholars Journal of Engineering and Technology, vol. 3, pp. 560-562, 2015.

[15] A. L. Wang, X. Y. Ma, and X. Yang, "Study on activity of iron tailings powder as concrete admixture," China Concrete, vol. 8, pp. 66-69, 2013.

[16] X. Y. Zhang, Q. Song, H. Li, and X. D. Fan, "Effect of iron tailings powder on properties of C40 concrete," Bulletin of the Chinese Ceramic Society, vol. 32, no. 12, pp. 2559-2563, 2013.

[17] Y. F. Hou and S. R. Zhao, "Effect of iron tailings powder on concrete properties," Fly Ash Comprehensive Utilization, vol. 3, pp. 17-24, 2015.

[18] China Engineering Construction Standardization Association, "Standard for durability assessment of concrete structures," China Construction Industry Press, Beijing, China, CECS 220-2007, 2007.

[19] J. C. Wang, J. H. Zhou, X. D. Wang, and C. Z. Mei, "Experimental study of the carbonation depth prediction model for waste fiber recycled concrete," Industrial Construction, vol. 48 , no. 3 , pp. $17-20+5,2018$.

[20] D. T. Niu, C. H. Li, and H. Song, "A model for predicting carbonation depth of concrete with multi-mineral admixtures," Journal of Xian University of Architecture and Technology, vol. 42, no. 4, pp. 464-467+472, 2010. 